Virginia Commonwealth University VCU Scholars Compass

2012

\title{
Structural changes of Pd-13 upon charging and oxidation/reduction
}

\section{J. Ulises Reveles}

Virginia Commonwealth University, jureveles@vcu.edu

\author{
A. M. Köster \\ Avenida Instituto Politecnico Nacional \\ P. Calaminici \\ Avenida Instituto Politecnico Nacional \\ S. N. Khanna \\ Virginia Commonwealth University, snkhanna@vcu.edu
}

Follow this and additional works at: http://scholarscompass.vcu.edu/phys_pubs

Part of the Physics Commons

Reveles, J. U., Koster, A. M., \& Calaminici, P., et al. Structural changes of Pd-13 upon charging and oxidation/reduction. The Journal of Chemical Physics, 136, 114505 (2012). Copyright (C) 2012 American Institute of Physics.

\section{Downloaded from}

http://scholarscompass.vcu.edu/phys_pubs/168

This Article is brought to you for free and open access by the Dept. of Physics at VCU Scholars Compass. It has been accepted for inclusion in Physics Publications by an authorized administrator of VCU Scholars Compass. For more information, please contact libcompass@vcu.edu. 


\title{
Structural changes of $\mathrm{Pd}_{13}$ upon charging and oxidation/reduction
}

\author{
J. Ulises Reveles, ${ }^{1, a)}$ A. M. Köster, ${ }^{2}$ P. Calaminici, ${ }^{2}$ and S. N. Khanna ${ }^{1, b)}$ \\ ${ }^{1}$ Department of Physics, Virginia Commonwealth University, Richmond, Virginia 23284-2000, USA \\ ${ }^{2}$ Departamento de Química, Cinvestav, Avenida Instituto Politécnico Nacional 2508, A.P. 14-740, \\ Mexico D.F. 07000, Mexico
}

(Received 29 November 2011; accepted 20 February 2012; published online 15 March 2012)

\begin{abstract}
First-principle generalized gradient corrected density functional calculations have been performed to study the stability of cationic and anionic $\mathrm{Pd}_{13}{ }^{+-}$, and neutral $\mathrm{Pd}_{13} \mathrm{O}_{2}$ clusters. It is found that while cationic $\mathrm{Pd}_{13}{ }^{+}$favors a $C_{s}$ geometry similar to the neutral $\mathrm{Pd}_{13}$, both anionic $\mathrm{Pd}_{13}{ }^{-}$and neutral $\mathrm{Pd}_{13} \mathrm{O}_{2}$ favor a compact $\sim I_{h}$ structure. A detailed analysis of the electronic structure shows that the stabilization of the delocalized $1 \mathrm{P}$ and $2 \mathrm{P}$ cluster orbitals, and the hybridization of the $1 \mathrm{D}$ orbitals with the oxygen atomic $p$ orbitals play an important role in the energetic ordering of $C_{s}$ and $\sim I_{h}$ isomers. A structural oscillation is predicted during an oxidation/reduction cycle of $\operatorname{Pd}_{13}$ in which small energy barriers between 0.3 and $0.4 \mathrm{eV}$ are involved. () 2012 American Institute of Physics. [http://dx.doi.org/10.1063/1.3692612]
\end{abstract}

\section{INTRODUCTION}

An interesting area in the field of clusters is the existence of isomers and their effect on the observed behaviors. The reduced size leads to atomic arrangements that are different from the bulk and many times, different atomic arrangements exhibit competing stability. ${ }^{1-8}$ For magnetic clusters, in addition to geometries, the clusters can have states of differing multiplicity that are close in energy. ${ }^{9-12}$ The presence of the isomers can lead to interesting effects particularly when the barriers separating the isomers are small and the isomers have differing properties. In this work, the term isomer will include configurations with energies per atom differing by around one hundredth of an electron volt or less. The observable properties are then be determined by the sampling of the various configurations as a function of temperature or other external influence. We investigated these interesting aspects in a recent work for the case of a $\mathrm{Pd}_{13}$ cluster. ${ }^{13}$ Unlike bulk $\mathrm{Pd}$, small $\mathrm{Pd}_{\mathrm{n}}$ clusters have finite spin magnetic moments. ${ }^{14}$ Theoretical studies indicated that a $\mathrm{Pd}_{13}$ cluster is marked by three isomeric forms, ${ }^{11,15,16}$ namely, a bi-layer $C_{s}$ ground state structure with buckled surfaces that can be regarded as a relaxed bulk fragment, another bi-layer structure in $C_{3 v}$ with flat surfaces that can be obtained by a slight rearrangement of atoms in the $C_{s}$ structure, and an icosahedral structure around $0.14 \mathrm{eV}$ above the ground state bi-layer structure which was considered the ground state in numerous previous works. ${ }^{17-20}$ The bi-layer $C_{s}$ and $C_{3 v}$ had lowest energy configurations with magnetic moment of $6.0 \mu_{\mathrm{B}}$ with states of lower multiplicity closer to the ground state. On the other hand, the icosahedral cluster had a magnetic moment of $8.0 \mu_{\mathrm{B}}$ with states of lower multiplicity separated from the ground state by a larger energy difference. The different multiplet structures of the isomers lead to different thermal behaviors. Whereas the magnetic moment of $C_{s}$ and $C_{3 v}$ structures decreased with

\footnotetext{
${ }^{a)}$ Electronic mail: jureveles@ vcu.edu.

b) Electronic mail: snkhanna@vcu.edu.
}

increasing temperature, the magnetic moment of the icosahedral structure remained largely unchanged under ordinary temperatures. ${ }^{13}$ We showed that the observed magnetic moment of $5.2 \mu_{\mathrm{B}}$ for the cluster can be accounted for by the $C_{s}$ and $C_{3 v}$ structures if one includes the spin excitations to the mutiplets at finite temperatures.

Palladium clusters are important oxidation catalysts and are widely used for $\mathrm{CO}$ oxidation, carbon cracking in a wide range of hydrocarbons, and other oxidation reactions. ${ }^{21,22}$ Since the reactions involve addition of reactants, it is important to understand how the various isomers bind with specific reactants? For example, oxidation reactions involve addition of oxygen to the cluster and the reduction of the oxidized species by the reactant. Oxygen generally binds by withdrawing charge and forming local bonds. How do the $\mathrm{O}$ atoms bind with various isomers and could $\mathrm{O}$ be used to tag one isomer compared to the other? If the barriers separating the isomers are small compared to the binding energies of adatoms, are there catalytic processes that could involve structural/spin fluctuations between the various isomers? Since many ligands bind by withdrawing or donating charge to clusters, how do the relative ordering of the isomers depend on the charged state of the cluster. The later is also important for identification of isomers in carefully planned experiments.

In this work, we offer to answer some of these questions by focusing on $\mathrm{Pd}_{13}$ clusters. We first examine the effect of charge on the relative ordering of isomers by carrying out electronic structure calculations on $\mathrm{Pd}_{13}{ }^{+}, \mathrm{Pd}_{13}$, and $\mathrm{Pd}_{13}{ }^{-}$ clusters. We are particularly interested to examine if the new bi-layer $C_{s}$ ground state of $\mathrm{Pd}_{13}$ could be seen in negative ion photodetachment experiments. ${ }^{5}$ We next consider the effect of adding an $\mathrm{O}_{2}$ molecule. Numerous experiments and theoretical studies in our and other groups indicate that the $\mathrm{O}-\mathrm{O}$ bond is broken upon addition to $\mathrm{Pd}_{13} .{ }^{23-26} \mathrm{In}$ fact, it is known that oxygen adsorbs dissociatively to form surface atomic oxygen on most transition metal surfaces. Molecularly absorbed $\mathrm{O}_{2}$ has been observed at low temperatures $\sim 80 \mathrm{~K}$ on nickel, palladium, and platinum surfaces, while at or higher than room 
temperature, oxygen is only present as adsorbed atoms. ${ }^{27-29}$ Therefore, we focus on the ground state for $\mathrm{OPd}_{13} \mathrm{O}$ clusters. Our objective here is twofold. We first examine the oxygen binding to the various isomers to explore if the icosahedral structure could be stabilized by adding $\mathrm{O}$ atoms. In previous papers, we had shown that the icosahedral isomer is stabilized by D-like cluster orbitals, while the $C_{s}$ structure is stabilized by P-like orbitals. How do these differing orbitals hybridize with $\mathrm{O}$ states. We then examine the energetics and barriers for an oxidation/reduction reaction where the $\mathrm{O}$ atoms are first added and the cluster is then reduced, to look at the progressions in various geometries/spin states. What role do the isomers play in these reactions? As mentioned before, the $C_{s}$ and $C_{3 v}$ isomers involve minor atomic re-arrangement. They are both composed of a base layer of an atom centered hexagon with another upper layer of six Pd atoms forming a triangle with three $\mathrm{Pd}$ atoms at each side. The only distinction is that the base hexagon in the $C_{s}$ structure is rotated by $60^{\circ}$ compared to the $C_{3 v}$ isomer and, as a consequence, a buckling of the surface atoms is observed. Because of this structural similarity, the two structures can be regarded as belonging to the same family. Consequently, in this work, we primarily focus on two isomers, namely, the $C_{s}$ and the icosahedral $\sim I_{h}$ clusters.

\section{THEORETICAL METHODS}

First-principle electronic structure calculations on cationic and anionic $\mathrm{Pd}_{13}{ }^{+/-}$and neutral $\mathrm{Pd}_{13} \mathrm{O}_{2}$ clusters were carried out within the framework of generalized gradient density functional theory. A linear combination of atomic orbitals-molecular orbital approach was employed where the cluster wave function is composed of a linear combination of Gaussian type orbitals centered at the atomic positions. The actual computations are based on the deMon2k (Ref. 30) code. The exchange and correlation effects were incorporated through the functional proposed by Perdew et $a{ }^{31}$ A variational fitting of the Coulomb potential was employed in order to avoid the calculation of four-center electron repulsion integrals, ${ }^{32}$ and the exchange-correlation potential was calculated via a numerical integration from the fitted density ${ }^{33}$ to speed up the computations. The palladium atom is described using a 18 electron quasi-relativistic effective core potential and the corresponding valence basis set as proposed by Andrae et al. ${ }^{34}$ and all electrons were treated explicitly using the double- $\zeta$ valence plus polarization basis sets $(621 / 41 / 1 *)$ for oxygen. ${ }^{35}$ The GEN-A2* auxiliary function set was used for both $\mathrm{Pd}$ and $\mathrm{O}$ atoms. ${ }^{36}$ To avoid spin contaminations the restricted open-shell Kohn-Sham methodology is employed. To determine the ground state geometries and lowest energy excited states, several initial configurations were tried. The search included reported $\mathrm{Pd}_{13}$ structures previously investigated by numerous authors using a variety of techniques ${ }^{11,15,17-21,37-39}$ as well as other structures available in our group on a variety of clusters. The structures were fully optimized, for various possible spin states, by employing a quasi-Newton method in delocalized internal coordinates ${ }^{40}$ without symmetry constraints. The transition state search was performed using a hierarchical transition state search algorithm. ${ }^{41}$ Resulting stationary points of both minima and transition state search were ascertained via a frequency analysis. The list of keywords used in the deMon2k input files, and the optimized $\mathrm{Pd}_{13}{ }^{+/-}$, $\mathrm{Pd}_{13} \mathrm{O}_{2}$ cluster structures along with their total energies are provided in the supplemental material. ${ }^{42}$ We would like to add that the use of generalized-gradient approximations for the calculation of reaction barriers has been shown to work reasonably well for the oxidative addition of $\mathrm{Pd}$ to $\mathrm{C}-\mathrm{H}$, $\mathrm{C}-\mathrm{C}$, and $\mathrm{C}-\mathrm{Cl}$ bonds by Diefenbach and Bickelhaupt. ${ }^{43}$ These studies also showed that relativistic effects are crucial and that the treatment of these effects at the quasi-relativistic level leads to only minor deviations from a more rigorous approach to relativity. These findings support our approach for the studies of $\mathrm{Pd}_{13} \mathrm{O}_{2}$ clusters.

\section{RESULTS AND DISCUSSION}

We first consider the effect of charging by calculating the ground state of $\mathrm{Pd}_{13}{ }^{+}$and $\mathrm{Pd}_{13}{ }^{-}$clusters. The theoretical studies indicate that the $C_{s}$ structure is the global minimum for the cationic $\mathrm{Pd}_{13}{ }^{+}$cluster with a spin magnetic moment of $5 \mu_{\mathrm{B}}$. A $C_{3 v}$ structure with spin moment of $7 \mu_{\mathrm{B}}$ was found $148 \mathrm{meV}$ higher in energy, and the closest $\sim I_{h}$ structure with a spin moment of $9 \mu_{\mathrm{B}}$ was $326 \mathrm{meV}$ higher in energy. Figure 1 shows the topology of the optimized clusters, and Table I presents the relative energies for the cationic $\mathrm{Pd}_{13}{ }^{+}$ clusters for various multiplicities. The relative ordering is the same as in neutral species as seen in our previous studies on $\mathrm{Pd}_{13}$ and these results are included in Table I for comparison. For $\mathrm{Pd}_{13}{ }^{+}$multiplicities above 10 are considerably higher in energy because of the occupation of an excited D-type cluster orbital. This is identical to the situation in the neutral $\mathrm{Pd}_{13}$ where the nonet is the highest accessible multiplicity. ${ }^{13}$ The electronic states indicate that in general the cationic species can be obtained by removing an electron from one of the single occupied molecular orbital of the neutral species. To understand the preference of the $C_{s}$ structure vs the $\sim I_{h}$, we analyzed the one electron energy levels of both neutral and cationic $\operatorname{Pd}_{13}$ clusters shown in Figures 2 and 3 . As discussed in our previous work on neutral $\mathrm{Pd}_{13},{ }^{13}$ the molecular or-
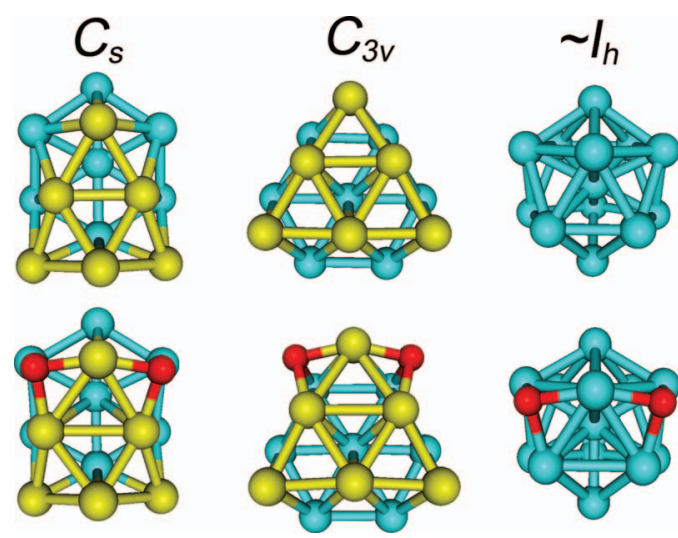

FIG. 1. Topology of optimized $\mathrm{Pd}_{13}{ }^{(+/-)}$and $\mathrm{Pd}_{13} \mathrm{O}_{2}$ isomers. The two $\mathrm{Pd}$ layers that form the $C_{s}$ and $C_{3 v}$ isomers are marked in blue and yellow color. The oxygen atoms are marked in red. 
TABLE I. Relative energies for the relevant multiplicities $(\mathrm{m})$ of the $C_{s}$ and $C_{3 v}$ bi-layer clusters, and the distorted icosahedral $\left(\sim I_{h}\right)$ neutral and cationic $\mathrm{Pd}_{13}{ }^{+}$clusters with respect to the, respectively, neutral ${ }^{7} C_{s}$ and cationic ${ }^{6} C_{s}$ ground states in $\mathrm{meV}$.

\begin{tabular}{|c|c|c|c|c|c|}
\hline \multirow[b]{2}{*}{ Structure } & \multicolumn{5}{|c|}{ Neutral $\operatorname{Pd}_{13}$} \\
\hline & $\mathrm{m}=1$ & $\mathrm{~m}=3$ & $\mathrm{~m}=5$ & $\mathrm{~m}=7$ & $\mathrm{~m}=9$ \\
\hline$C_{s}$ & 158 & 128 & 104 & $\mathbf{0}$ & 213 \\
\hline$C_{3 v}$ & 153 & 131 & 108 & 99 & 295 \\
\hline \multirow[t]{2}{*}{$\sim I_{h}$} & 774 & 630 & 523 & 341 & 134 \\
\hline & \multicolumn{5}{|c|}{ Cationic $\mathrm{Pd}_{13}{ }^{+}$} \\
\hline Structure & $\mathrm{m}=2$ & $\mathrm{~m}=4$ & $\mathrm{~m}=6$ & $\mathrm{~m}=8$ & $\mathrm{~m}=10$ \\
\hline$C_{s}$ & 157 & 106 & $\mathbf{0}$ & 21 & 391 \\
\hline$C_{3 v}$ & 184 & 268 & 198 & 148 & 506 \\
\hline$\sim I_{h}$ & 803 & 688 & 630 & 462 & 326 \\
\hline
\end{tabular}

bitals of both $C_{s}$ and $\sim I_{h}$ structures present relatively well defined $1 \mathrm{~S}, 1 \mathrm{P}, 1 \mathrm{D}$, and $2 \mathrm{P}$ delocalized orbitals characteristics of metallic and some bimetallic clusters, ${ }^{44-51}$ in addition to localized d-type atomic orbitals marked by lowercase letters. According to our analysis, the extra stabilization that favors $C_{s}$ structures for both neutral and cationic $\mathrm{Pd}_{13}$ arises from the stabilization of both $1 \mathrm{P}$ and $2 \mathrm{P}$ orbitals, whereas the $\sim I_{h}$ configurations have deeper 1D states.

In contrast with the neutral and cationic species, our calculations on the anionic $\mathrm{Pd}_{13}{ }^{-}$found that the more stable structure is the $\sim I_{h}$ configuration with a spin moment of $7 \mu_{\mathrm{B}}$,

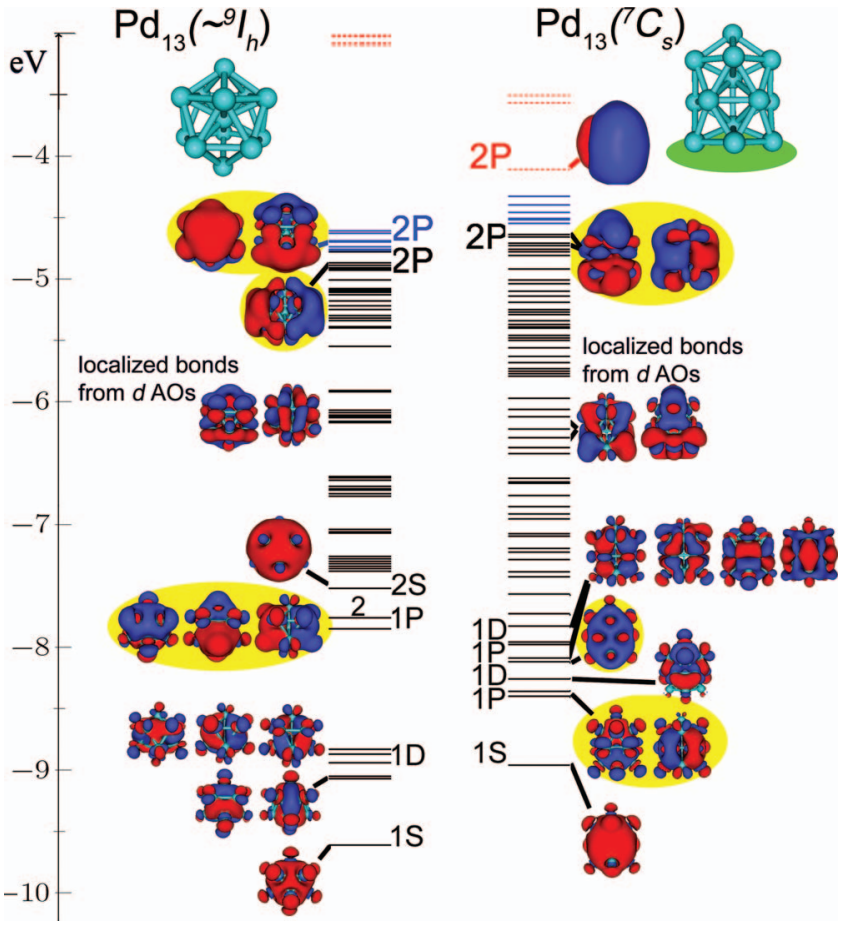

FIG. 2. One-electron energy levels and electron charge density of the ${ }^{9} \sim I_{h}$ and ${ }^{7} C_{s} \mathrm{Pd}_{13}$ neutral clusters. The continuous black and blue lines correspond, respectively, to the doubly and single occupied levels, whereas the dotted lines correspond to the unoccupied levels. The degeneracy of the $P$ and D orbitals is marked. The angular momentum is marked and the delocalized $P$ orbitals are highligthted on yellow. The optimized geometries are also shown where the green oval marks the most stable isomer.

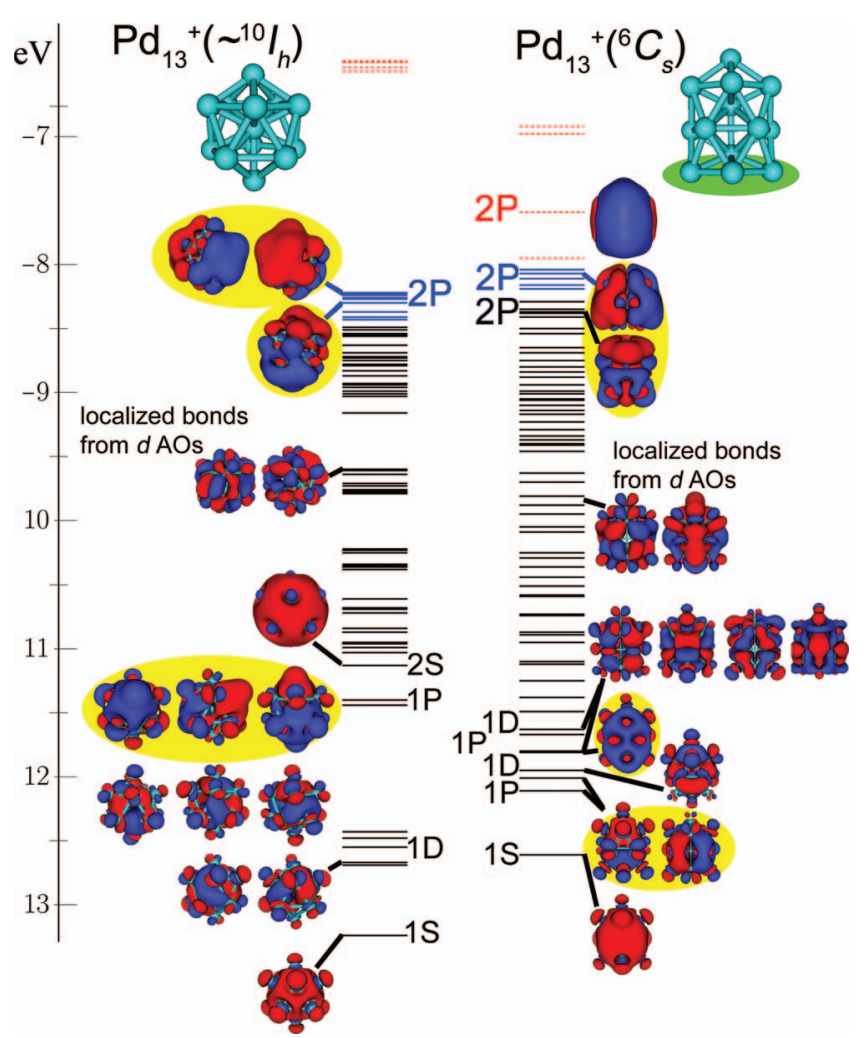

FIG. 3. One-electron energy levels and electron charge density of the ${ }^{10} \sim I_{h}$ and ${ }^{6} C_{s}$ cationic $\mathrm{Pd}_{13}{ }^{+}$clusters. See caption of Figure 2 .

followed by a $C_{s}$ structure with a spin magnetic moment of $5 \mu_{\mathrm{B}} 131 \mathrm{meV}$ higher in energy. Table II presents the relative energies for the anionic $\mathrm{Pd}_{13}{ }^{-}$isomers for various multiplicities. An analysis of the one electron energy levels and molecular orbitals (Figure 4) shows that the addition of one electron to the neutral species preferentially stabilizes the 1D orbitals in the $\sim I_{h}$ structure (reduced 1S-1D spacing), and this is how this geometry now results as the anionic $\mathrm{Pd}_{13}{ }^{-}$ground state. Further, we note that the $1 \mathrm{D}$ cluster orbitals in the $\sim I_{h}$ structure show $2 / 3$ degeneracy which also indicates a rather high symmetric configuration. Such a subtle interplay of the electronic structure of the neutral and charged $\mathrm{Pd}_{13}$ cluster and the stability of its isomers can be expected to determine the reactivity properties of the cluster.

Recently we have demonstrated the existence of a geometrical transition from compact to a pseudo planar geometry for a supported $\mathrm{Pd}_{4}$ cluster upon the absorption of an oxygen atom. ${ }^{52}$ To investigate if the oxygen absorption could also stabilize a given geometry of the $\operatorname{Pd}_{13}$ cluster we calculate the $\mathrm{Pd}_{13} \mathrm{O}_{2}$ neutral species. Starting from several possible initial

TABLE II. Relative energies for the relevant multiplicities (m) of the $C_{s}$ and $C_{3 v}$ bi-layer clusters, and the distorted icosahedral $\left(\sim I_{h}\right)$ anionic $\mathrm{Pd}_{13}{ }^{-}$ clusters with respect to the ${ }^{8} \sim I_{h}$ ground state in meV.

\begin{tabular}{lccccc}
\hline \hline Structure & $\mathrm{m}=2$ & $\mathrm{~m}=4$ & $\mathrm{~m}=6$ & $\mathrm{~m}=8$ & $\mathrm{~m}=10$ \\
\hline$C_{s}$ & 155 & 109 & 73 & 91 & 674 \\
$C_{3 v}$ & 212 & 150 & 127 & 196 & 909 \\
$\sim I_{h}$ & 448 & 300 & 127 & 0 & 1175 \\
\hline \hline
\end{tabular}




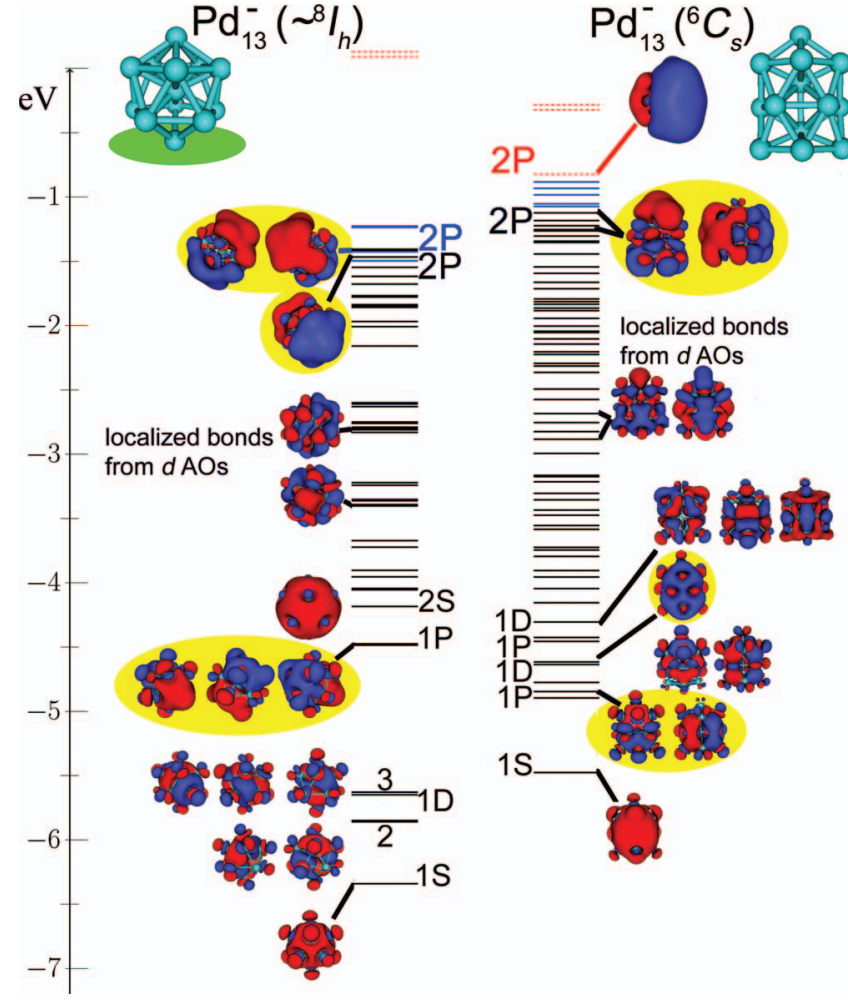

FIG. 4. One-electron energy levels and electron charge density of the ${ }^{8} \sim I_{h}$ and ${ }^{6} C_{s}$ anionic $\mathrm{Pd}_{13}{ }^{-}$clusters. See caption of Figure 2.

geometries and spin states, an $\mathrm{O}_{2}$ molecule was approached to a neutral $\operatorname{Pd}_{13}$ cluster and the system was fully optimized without constraints. Our results show, that as in the case of the pure $\mathrm{Pd}_{13}$ cluster, the $\mathrm{Pd}_{13} \mathrm{O}_{2}$ presents three typical topologies $C_{s}, C_{3 v}$, and $\sim I_{h}$ shown in Figure 1. In all attempted calculations the $\mathrm{O}_{2}$ molecule dissociated and bound atomically to the $\mathrm{Pd}_{13}$ cluster, in agreement with the experimental reports discussed in the Introduction. ${ }^{27-29}$ Interestingly, the $\mathrm{Pd}_{13} \mathrm{O}_{2}$ ground state was found to be a $\sim I_{h}$ geometry with a spin magnetic moment of $2 \mu_{\mathrm{B}}$, followed by a $C_{s}$ structure $656 \mathrm{meV}$ higher in energy. Relative energies for the three found topologies are given in Table III. In a recent experimental study on the reactivity of $\mathrm{O}_{2}$ to free palladium clusters Anderson and Rosén ${ }^{26}$ found that reaction probability of $\mathrm{O}_{2}$ absorption on $\mathrm{Pd}_{13}$ was greater than for neighboring sizes. We then try to understand if this enhanced reactivity can be rooted on the nature of the bonding and the possibility of geometrical changes on $\mathrm{Pd}_{13}$ and $\mathrm{Pd}_{13} \mathrm{O}_{2}$.

To first investigate why a $\mathrm{Pd}_{13} \mathrm{O}_{2}$ is more stable in a $\sim I_{h}$ geometry vs a $C_{s}$ geometry in $\operatorname{Pd}_{13}$ we analyzed the one electron energy levels and molecular orbitals. Figure 5 shows $\operatorname{Pd}_{13}$

TABLE III. Relative energies for the relevant multiplicities of the $C_{s}$ and $C_{3 v}$ bi-layer clusters, and the distorted icosahedral $\left(\sim I_{h}\right)$ neutral $\mathrm{Pd}_{13} \mathrm{O}_{2}$ clusters with respect to the ${ }^{3} \sim I_{h}$ ground state in $\mathrm{meV}$.

\begin{tabular}{lccccc}
\hline \hline Structure & $\mathrm{m}=1$ & $\mathrm{~m}=3$ & $\mathrm{~m}=5$ & $\mathrm{~m}=7$ & $\mathrm{~m}=9$ \\
\hline$C_{S}$ & 672 & 599 & 611 & 707 & 985 \\
$C_{3 v}$ & 699 & 664 & 727 & 948 & 1243 \\
$\sim I_{h}$ & 111 & 0 & 80 & 258 & 606 \\
\hline \hline
\end{tabular}

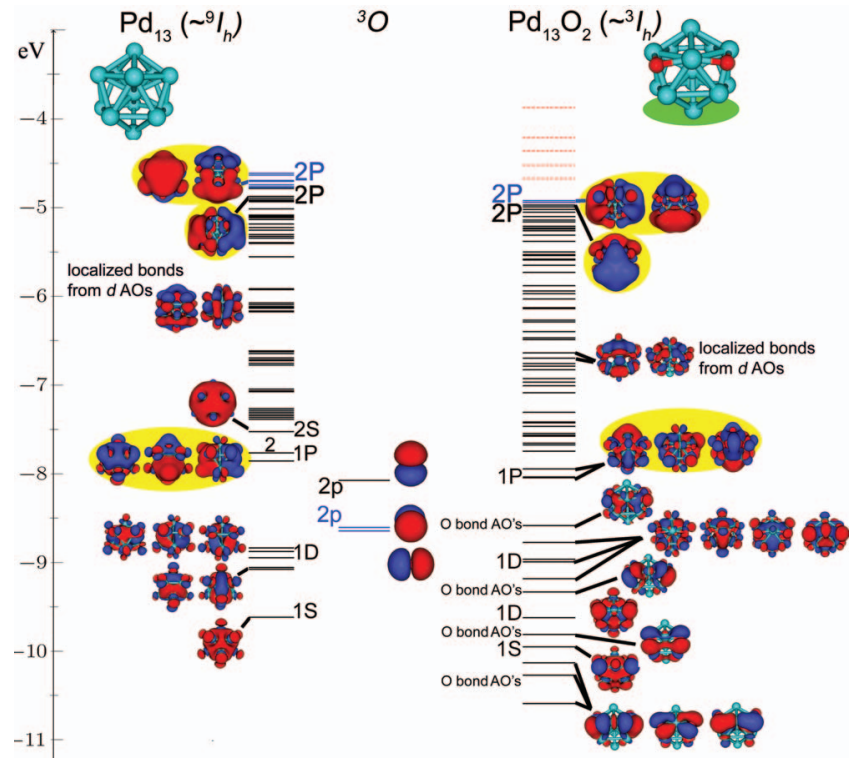

FIG. 5. One-electron energy levels and electron charge density of the $\mathrm{Pd}_{13}\left({ }^{9} \sim I_{h}\right),{ }^{3} \mathrm{O}$, and $\mathrm{Pd}_{13} \mathrm{O}_{2}\left({ }^{3} \sim I_{h}\right)$ neutral species. See caption of Figure 2. The oxygen atoms are marked in red.

$\left(\sim I_{h}\right), \mathrm{O}$ atom and $\mathrm{Pd}_{13} \mathrm{O}_{2}\left(\sim I_{h}\right)$ energy levels. As can be seen in Fig. 5, the $4 p$ electrons of $\mathrm{O}$ lie just above the 1D orbitals of $\mathrm{P}_{13}\left(\sim I_{h}\right)$ and readily interact with them forming six bonding states that lie from -8.5 to $-10.5 \mathrm{eV}$ and which are mixed with the $1 \mathrm{D}$ orbitals in the $\mathrm{Pd}_{13} \mathrm{O}_{2}\left(\sim I_{h}\right)$ cluster. In addition, the $1 \mathrm{P}$ and $2 \mathrm{P}$ states are stabilized and move to lower energy positions.

Figure 6 shows the respective energy levels for the $\mathrm{Pd}_{13}$ $\left(C_{s}\right), \mathrm{O}$ atom, and $\mathrm{Pd}_{13} \mathrm{O}_{2}\left(C_{s}\right)$ species. In this case the oxygen $p$ electrons lie around the same energy of the $1 \mathrm{P}$ and $1 \mathrm{D}$ lev-
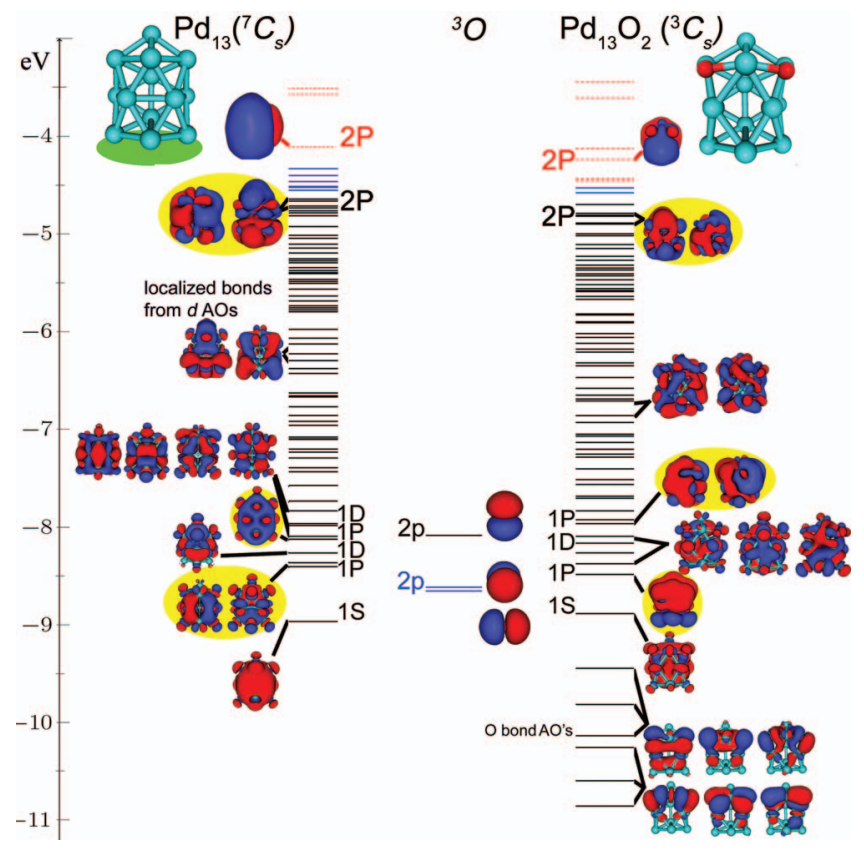

FIG. 6. One-electron energy levels and electron charge density of the $\mathrm{Pd}_{13}\left({ }^{7} C_{s}\right),{ }^{3} \mathrm{O}$, and $\mathrm{Pd}_{13} \mathrm{O}_{2}\left({ }^{3} C_{s}\right)$ neutral species. See caption of Figure 2. The oxygen atoms are marked in red. 


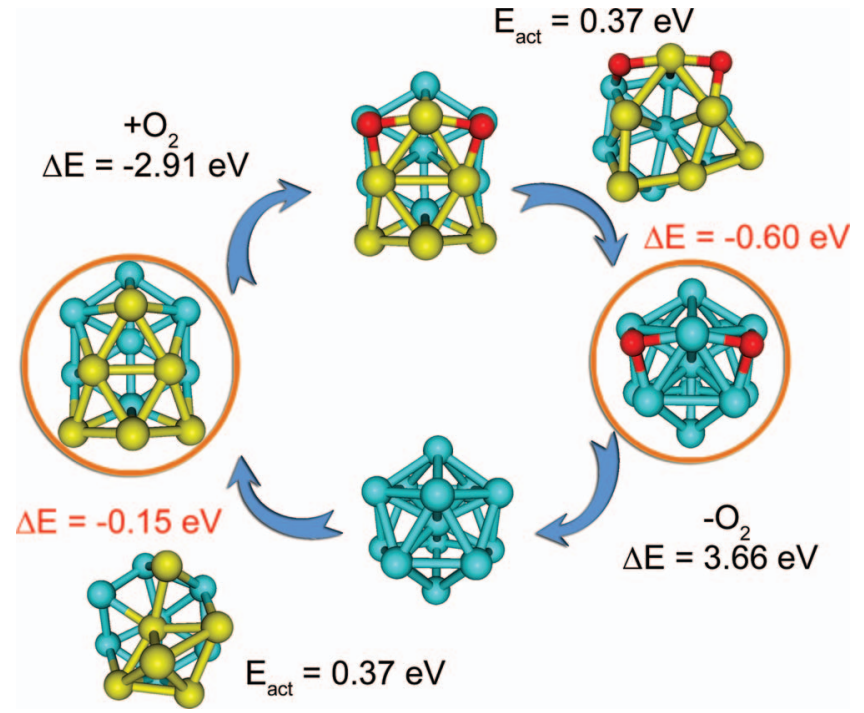

FIG. 7. Structural oscillations in $\mathrm{Pd}_{13}$ during an oxidation/reduction process.

els and form bonding states with a less strong interaction and hybridization. In the $\mathrm{Pd}_{13} \mathrm{O}_{2}\left(C_{s}\right)$ cluster the oxygen bonding states all group together around from -9.5 to $-10.8 \mathrm{eV}$, and do not mix with the 1P and 1D states whose position, as well as that of the $2 \mathrm{P}$ orbitals are not significantly modified from the $\operatorname{Pd}_{13}\left(\sim C_{s}\right)$ cluster. In this way, the fact that the oxygen $p$ orbitals preferentially hybridize with the $1 \mathrm{D}$ states of the $\operatorname{Pd}_{13}\left(\sim I_{h}\right)$, and that for this isomer the interaction is stronger determines the stability of the resulting oxidized species.

The observation that the ground state of the bare $\mathrm{Pd}_{13}$ has a $C_{s}$ geometry while the $\mathrm{Pd}_{13} \mathrm{O}_{2}$ has an icosahedral $\left(\sim I_{h}\right) \mathrm{Pd}_{13}$ core does raise an interesting structural progression during an oxidation/reduction reaction. Such a process is described in Fig. 7. Consider starting with a isolated $\mathrm{Pd}_{13}$ and adding an $\mathrm{O}_{2}$ molecule. The binding energy of the $\mathrm{O}_{2}$ molecule is $2.91 \mathrm{eV}$ while our studies indicate the barrier for transitioning to the icosahedral $\mathrm{Pd}_{13} \mathrm{O}_{2}$ ground state is $0.37 \mathrm{eV}$. Further, oxygen reduction by $\mathrm{CO}$ oxidation will produce $\mathrm{Pd}_{13}$ in a $\sim I_{h}$ geometry which will then rearrange to the more stable $C_{s}$ geometry after overcoming an energy barrier of $0.37 \mathrm{eV}$. The removal of oxygen from magnesia supported $\mathrm{Pd}_{13} \mathrm{O}_{\mathrm{x}}$ clusters by $\mathrm{CO}$ oxidation has recently been experimentally investigated byHabibpour et al. ${ }^{53}$ Their results show that for temperatures as low as $200 \mathrm{~K}$, formation of $\mathrm{CO}_{2}$ results from a reaction of carbon monoxide with a highly activated, molecularly bound oxygen species. ${ }^{53}$ The structural changes of $\mathrm{Pd}_{13}$ upon oxidation/reduction is depicted in Figure 7 and can be divided into the following steps:

\begin{tabular}{lr}
\hline \hline & $\Delta \mathrm{E}(\mathrm{eV})$ \\
\hline $\mathrm{Pd}_{13}\left({ }^{7} C_{s}\right)+{ }^{3} \mathrm{O}_{2} \rightarrow \mathrm{Pd}_{13} \mathrm{O}_{2}\left({ }^{3} C_{s}\right)$ & -2.91 \\
$\mathrm{Pd}_{13} \mathrm{O}_{2}\left({ }^{3} C_{s}\right) \rightarrow \mathrm{Pd}_{13} \mathrm{O}_{2}\left({ }^{3} \sim I_{h}\right)[\mathrm{TS}]$ & 0.37 \\
$\mathrm{Pd}_{13} \mathrm{O}_{2}\left({ }^{3} C_{s}\right) \rightarrow \mathrm{Pd}_{13} \mathrm{O}_{2}\left({ }^{3} \sim I_{h}\right)$ & -0.60 \\
$\mathrm{Pd}_{13} \mathrm{O}_{2}\left({ }^{3} \sim I_{h}\right) \rightarrow \mathrm{Pd}_{13}\left({ }^{9} \sim I_{h}\right)+{ }^{3} \mathrm{O}_{2}$ & 3.66 \\
$\operatorname{Pd}_{13}\left({ }^{9} \sim I_{h}\right) \rightarrow \operatorname{Pd}_{13}\left({ }^{9} C_{s}\right)[\mathrm{TS}]$ & 0.37 \\
$\operatorname{Pd}_{13}\left({ }^{9} \sim I_{h}\right) \rightarrow \operatorname{Pd}_{13}\left({ }^{7} C_{s}\right)$ & -0.15 \\
\hline \hline
\end{tabular}

\section{CONCLUSIONS}

In summary, we have investigated the stability of cationic and anionic $\mathrm{Pd}_{13}{ }^{+-}$and neutral $\mathrm{Pd}_{13} \mathrm{O}_{2}$ clusters and shown how the location of the delocalized 1P, 1D, and 2P molecular orbitals, and the degree of hybridization between the atomic oxygen $p$ orbitals and the molecular 1D orbitals determines the order of stability of the possible isomers. A structural change is predicted for the oxidation/reduction of $\mathrm{Pd}_{13}$ which involves energy barriers between $0.3 \mathrm{eV}$ and $0.4 \mathrm{eV}$. This small energy barriers and the possibility of geometrical rearrangements seems to be the reason for the enhanced reactivity of $\mathrm{Pd}_{13}$ towards $\mathrm{O}_{2}$. We are in the process of exploring a variety of atoms that can interact with the molecular 1D orbitals to correlate with the observed catalytic behavior.

\section{ACKNOWLEDGMENTS}

S.N.K. acknowledges support from the (U. S.) Department of Energy (DOE) through Grant No. DE-FG0211ER16213 for work on charged clusters. J.U.R. and S.N.K. are grateful to Air Force Office of Scientific Research (AFOSR) Award No. FA9550-08-1-0400PC for work on oxidation by clusters. A.M.K. and P.C. acknowledge funding from ICyTDF (PIFUTP08-87 and PICCO-10-47) and CONACyT (60117-U, 130726, and CIAM 107310). Parts of the calculations were performed at the WESTGRID, Canada.

${ }^{1}$ S. K. Nayaka, B. K. Rao, S. N. Khanna, and P. Jena, Chem. Phys. Lett. 259, 588 (1996).

${ }^{2}$ X. H. Guo, H. F. Grutzmacher, and N. M. M. Nibbering, Eur. J. Mass Spectrom. 6, 357 (2000).

${ }^{3}$ M. S. Ford, M. L. Anderson, M. P. Barrow, D. P. Woodruff, T. Drewello, P. J. Derrick, and S. R. Mackenzie, Phys. Chem. Chem. Phys. 7, 975 (2005).

${ }^{4}$ D. Harding, M. S. Ford, T. R. Walsh, and S. R. Mackenzie, Phys. Chem. Chem. Phys. 9, 2130 (2007).

${ }^{5}$ W. Huang and L.-S. Wang, Phys. Chem. Chem. Phys. 11, 2663 (2009).

${ }^{6}$ N. O. Jones, J. U. Reveles, S. N. Khanna, D. E. Bergeron, P. J. Roach, and A. W. Castleman, Jr., Chem. Phys. 124, 154311 (2006).

${ }^{7}$ C. E. Jones, Jr., P. A. Clayborne, J. U. Reveles, J. J. Melko, U. Gupta, S. N. Khanna, and A. W. Castleman, Jr., J. Phys. Chem. A 112, 13316 (2008).

${ }^{8}$ R. Caballero, C. Quintanar, A. M. Köster, S. N. Khanna, and J. U. Reveles, J. Phys. Chem. C 112, 14919 (2008).

${ }^{9}$ N. O. Jones, S. N. Khanna, T. Baruah, M. R. Pederson, W.-J. Zheng, J. M. Nilles, and K. H. Bowen, Phys. Rev. B 70, 134422 (2004).

${ }^{10}$ F. W. Payne, W. Jiang, and L. A. Bloomfield. Phys. Rev. Lett. 97, 193401 (2006).

${ }^{11}$ T. Futschek, M. Marsman, and J. Hafner, J. Phys.: Condens. Matter 17, 5927 (2005).

${ }^{12}$ P. Borrmann, B. Diekmann, and E. R. Hilf, Surf. Rev. Lett. 3, 463 (1996).

${ }^{13}$ A. M. Köster, P. Calaminici, E. Orgaz, D. R. Roy, J. U. Reveles, and S. N. Khanna, J. Am. Chem. Soc. 133, 12192 (2011).

${ }^{14}$ A. J. Cox, J. G. Louderback, S. E. Apsel, and L. A. Bloomfield, Phys. Rev. B 49, 12295 (1994).

${ }^{15}$ C. M. Chang and M. Y. Chou, Phys. Rev. Lett. 93, 133401 (2004).

${ }^{16}$ L.-L. Wang and D. D. Johnson, Phys. Rev. B 75, 235405 (2007).

${ }^{17}$ V. Kumar and Y. Kawazoe, Phys. Rev. B 66, 144413 (2002).

${ }^{18}$ P. Nava, M. Sierka, and R. Ahlrichs, Phys. Chem. Chem. Phys. 5, 3372 (2003).

${ }^{19}$ J. Rogan, G. García, J. A. Valdivia, W. Orellana, A. H. Romero, R. Ramírez, and M. Kiwi, Phys. Rev. B 72, 115421 (2005).

${ }^{20}$ F. Aguilera-Granja, A. Vega, J. Rogan, W. Orellana, and G. García, Eur. Phys. J. D 44, 125 (2007).

${ }^{21}$ D. Ciuparu, M. R. Lyubovsky, E. Altman, L. D. Pfefferle, and A. Datye, Catal. Rev. - Sci. Eng. 44, 593 (2002). 
${ }^{22}$ S. Penner, P. Bera, S. Pedersen, L. T. Ngo, J. J. W. Harris, and C. T. Campbell, J. Phys. Chem. B 110, 24577 (2006).

${ }^{23}$ P. A. Hintz and K. M. Ervin, J. Chem. Phys. 103, 7897 (1995).

${ }^{24}$ F. von Gynz-Rekowski, G. Ganteför, and Y. D. Kim, Eur. Phys. J. D 43, 81 (2007).

${ }^{25}$ B. Huber, H. Häkkinen, U. Landman, and M. Moseler, Comput. Mater. Sci. 35, 371 (2006).

${ }^{26}$ A. Rosén and M. J. Andersson, J. Phys.: Condens. Matter 22, 334223 (2010).

${ }^{27}$ C. N. R. Rao, P. V. Kamath, and S. Yashanath, Chem. Phys. Lett. 88, 13 (1982).

${ }^{28}$ P. V. Kamath and C. N. R. Rao, J. Phys. Chem. 88, 464 (1984).

${ }^{29}$ J. Schmidt, Ch. Stuhlmann, and H. Ibach, Surf. Sci. 284, 121 (1993).

${ }^{30}$ A. M. Köster et al. deMon2k, V. 3.0; The International deMon Developers Community: Cinvestav, México, 2006; see http://www.deMon-software.com.

${ }^{31}$ J. P. Perdew, K. Burke, and M. Ernzerhof, Phys. Rev. Lett. 77, 3865 (1996).

${ }^{32}$ B. I. Dunlap, J. W. D. Connolly, and J. R. Sabin, J. Chem. Phys. 71, 3396 (1979).

${ }^{33}$ A. M. Köster, R. Flores-Moreno, and J. U. Reveles, J. Chem. Phys. 121, 681 (2004).

${ }^{34}$ D. Andrae, U. Haeussermann, M. Dolg, H. Stoll, and H. Preuss, Theor. Chim. Acta 77, 123 (1990).

${ }^{35}$ N. Godbout, D. R. Salahub, J. Andzelm, and E. Wimmer, Can. J. Chem. 70, 560 (1992).

${ }^{36}$ P. Calaminici, F. Janetzko, A. M. Köster, R. Mejia-Olvera, and B. ZuñigaGuitierrez, J. Chem. Phys. 126, 044108 (2007).

${ }^{37}$ M. Moseler, H. Hakkinen, R. N. Barnett, U. Landman, Phys. Rev. Lett. 12, 2545 (2001)

${ }^{38}$ Y. Sun, R. Fournier, and M. Zhang, Phys. Rev. A 79, 043202 (2009).
${ }^{39}$ S. Barman, D. G. Kanhere, and G. P. Das. J. Phys.: Condens. Matter 21, 396001 (2010).

${ }^{40}$ J. U. Reveles and A. M. Köster, J. Comput. Chem. 25, 1109 (2004).

${ }^{41}$ J. M. del Campo and A. M. Köster, J. Chem. Phys. 129, 024107 (2008).

${ }^{42}$ See supplementary material at http://dx.doi.org/10.1063/1.3692612 for the total energies [a.u.] and Cartesian coordinates $[\AA]$ of the optimized $\mathrm{Pd}_{13}{ }^{+}$, $\mathrm{Pd}_{13}{ }^{-}$, and $\mathrm{Pd}_{13} \mathrm{O}_{2}$ isomers; the (approximated) symmetry point group and molecular spin multiplicity are also given. A list of the keywords used in the deMon2k input files is provided.

${ }^{43}$ A. Diefenbach and F. M. Bickelhaupt, J. Chem. Phys. 115, 4030 (2001).

${ }^{44}$ W. D. Knight, W. A. deHeer, W. A. Saunders, M. Y. Chou, and M. L. Cohen, Phys. Rev. Lett. 52, 2141 (1984).

${ }^{45}$ K. Jug, B. Zimmermann, P. Calaminici, and A. M. Köster, J. Chem. Phys. 116, 4497 (2002).

${ }^{46}$ K. Jug, B. Zimmermann, and A. M. Köster, Int. J. Quantum. Chem. 90, 594 (2002).

${ }^{47}$ E. Janssens, S. Neukermans, and P. Lievens, Curr. Opin. Solid State Mater. Sci. 8, 185 (2004).

${ }^{48}$ D. E. Bergeron, P. J. Roach, A. W. Castleman, Jr., N. O. Jones, and S. N. Khanna, Science 307, 231 (2005).

${ }^{49}$ J. Hartig, A. Stösser, P. Hauser, and H. A. Schnöckel, Angew Chem., Int. Ed. 46, 1658 (2007).

${ }^{50}$ J. J. Melko, P. A. Clayborne, C. E. Jones, Jr., J. U. Reveles, U. Gupta, S. N. Khanna, and A. W. Castleman, Jr., J. Phys. Chem. A 114, 2045 (2010).

${ }^{51}$ V. M. Medel, J. U., Reveles, S. N. Khanna, V. Chauhan, P. Sen, and A. W. Castleman, Jr., Proc. Natl. Acad. Sci. U.S.A. 108, 10062 (2011).

${ }^{52}$ S. Ong and S. N. Khanna, J. Phys. Chem. C 115, 20217 (2011).

${ }^{53}$ V. Habibpour, Z. W. Wang, R. E. Palmer, and U. Heiz, J. Appl. Sci. 11, 1164 (2011) 